6 Rhodes T, Ball A, Stimson GV, Kobyshcha Y, Fitch C, Pokrovsky V, et al. HIV infection associated with drug injecting in the newly independent states, eastern Europe: the social and economic context of epidemics. Addiction 1999;94:1323-36

McKee M. Substance use and social and economic transition: the need for evidence. Int J Drug Policy 2002;13:453-9.

8 European Bank for Reconstruction and Development. Transition report. energy in transition. London: EBRD, 2001.

9 Farmer P, Connors M, Simmons J. Women, poverty and AIDS: sex, drugs and structural violence. Monroe, MN: Common Courage Press, 1996.

10 Pedersen D. Political violence, ethnic conflict, and contemporary wars: broad implications for health and social well-being. Soc Sci Med 2002;55:175-90.

11 Rhodes T, Sarang A, Bobrik A, Bobkov E, Platt L. HIV transmission and HIV prevention associated with injecting drug use in the Russian Federation. Int J Drug Policy 2004:15:1-16.

12 Godinho J, Jaganjac N, Eckertz D, Renton A, Novotny T, Garbus L. HIV AIDS in the western Balkans: priorities for early prevention in high-risk environment. Washington, DC: World Bank, 2004

13 United Nations Development Programme. Building blocks for reform and recovery: mid-term report 2002-2003. Belgrade: UNDP, 2003.

14 Duff CH. Balkan briefing: Reflections on the health of a refugee population. J Epidemiol Community Health 1999;53:578-9.

15 United Nations Development Programme Human development report Yugoslavia. Belgrade: UNDP, 1997.
16 Gordy E. The culture of power in Serbia: nationalism and the destruction of Alternatives University Park, PA. Pennsylvania State University Press, 1999.

7 Ministry of Social Affairs of Republic of Serbia. poverty reduction strategy paper for Serbia. Belgrade: Ministry of Social Affairs, 2003.

18 Horton R. Croatia and Bosnia: the imprints of war: restoration. Lancet 1999;353:2223-8.

19 Carballo M, Puvacic S, Zeric D. Implications of complex emergencies, uprooting and forced migration on risk of HIV/AIDS: the case of Bosnia and Herzegovina. Twelfth World AIDS Conference, Geneva, June 1998: Abstract No 244/14139.

20 Olujic M. Embodiment of terror: gender violence in peacetime and wartime in Croatia and Bosnia and Herzegovina, Med Anthropol $Q$ 1998;12:31-50.

21 Carballo M, Smajkic A, Zeric D, Dzidowska M, Gebre-Medhin J, Van Halem J. Mental health and copying in a war situation: the case of Bosnia and Herzegovina.J Bio Soc Sci 2004;36:463-77.

22 Djilas A. A profile of Slobodan Milosevic. Foreign Affairs 1993;72:81-96.

23 European Roma Rights Centre. Roma: fundamental rights in former Yugoslavia. Budapest: ERRC, 2002.

24 Argovino T. Serbia continues to fail ethnic Albanians. Lancet 1997;350:1757.

25 Pyle GF, Thompson CR, Oreskovic S, Bagaric I. Rebuilding the healthcare system in Mostar: challenge and opportunity. Croatian Med J 1998:39:3.

26 Wong T. Rapid assessment of Serbia HIV/AIDS/STI surveillance system. Ottawa: Centre for Infectious Disease Prevention and Control, 2002.

\title{
Croatian healthcare system in transition, from the perspective of users
}

\author{
Miroslav Mastilica, Sanja Kušec
}

Reform of the Croatian healthcare system focused mainly on centralising financing, rationing services, and encouraging the provision of private health services with incentives. Although these changes may have contained costs, they have increased inequality of access to health care and proved highly unpopular with users

In Croatia, as in other countries in transition, healthcare reform was a necessary process that went alongside general changes in the political system and economy. New objectives and measures were defined in the early 1990s, adopted by the Croatian parliament, and came into force with the new Health Care Act and Health Insurance Act in 1993.

The principal motive for healthcare reform was dissatisfaction with the existing healthcare system: the government was dissatisfied with the economic inefficiency of the system, doctors were dissatisfied with their income, and people were mainly dissatisfied with access (long waiting times), the behaviour of staff, and regular shortages of drugs. ${ }^{12}$ Consequently, healthcare reform primarily focused on financing, rationing of services, and introduction of private incentives in the provision of services.

\section{Healthcare reform-objectives, measures, problems}

Centralisation of financing resulted in the establishment of a central insurance fund in 1990, responsible for implementation of health policies and financing and control of health services. New standards of insured rights were established. Compulsory health insurance covered a restricted range of health services, reducing the volume of services covered, and the list of

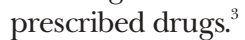

Financial management of health services was introduced to control expenditure. Health providers were contracted by the state insurance fund and paid only for providing the determined standard of services. Limiting services was thus established as a control mechanism, mainly in primary health care, and doctors became responsible for any overuse of services. Cost sharing (copayments) was introduced for almost all health services and drugs. Exemptions were made for children and students, people receiving the minimum income, the unemployed, people aged 65 or more, war veterans, people in military service, and those with chronic mental illness or communicable diseases.

Voluntary health insurance was introduced either as supplementary insurance (for higher standard or quality of care, such as for extra services and drugs excluded from the compulsory insurance plan, and for amenities) or as private health insurance (limited to the highest income groups (annual income $\geq$ US\$35 000).

Privatisation of services, as one of the main goals of health reform, took two basic forms-private practice in privately owned facilities provided by self employed doctors, and private practitioners in rented offices of public health institutions.

\section{Problems with the reforms}

Various measures aimed at cost containment-such as rationing of services, limitation of services provided, penalties for excessive prescribing or referrals, a limited list of approved drugs, reductions in health budgets, increases in copayments-have been implemented over the past 10 years in the Croatian healthcare system, but with only limited success and acceptance from providers and the public.
Department of Medical Sociology, Andrija Štampar School of Public Health, Medical

School, University of Zagreb,

Rockefellerova 4,

HR-10000 Zagreb, Croatia

Miroslav Mastilica associate professor

Department of Educational Technology, Andrija Stampar School of Public Health

Sanja Kušec master of science in public health

Correspondence to:

M Mastilica mmastil@snz.hr

BMJ 2005;331:223-7 


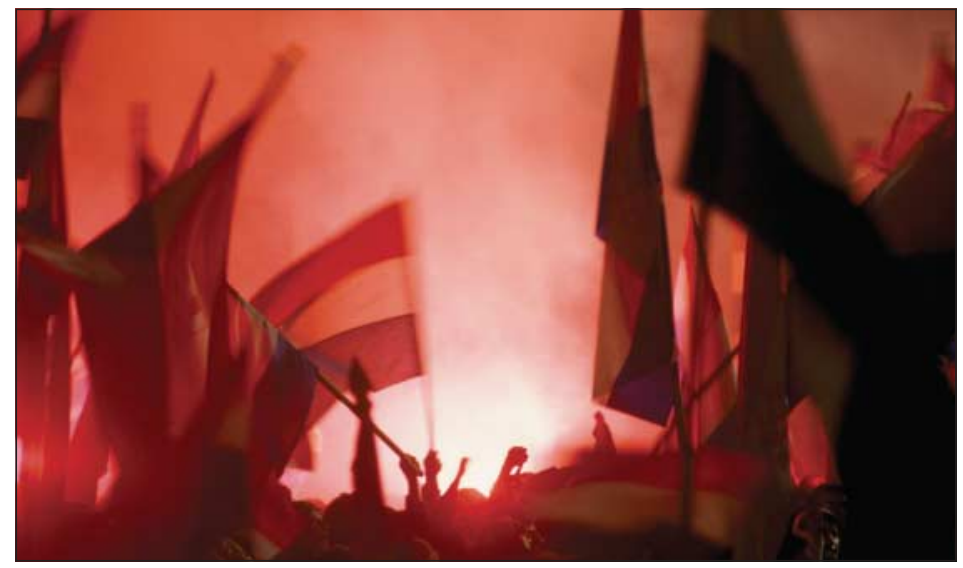

After the euphoria, many Croatians believe their health reforms have left them worse off

The growing scarcity of resources and limited health services and drugs covered by the basic health insurance have led to a lower standard of health care. This is particularly noticeable in the provision of preventive services. The drastic decline in numbers of preventive check ups and home visits has potential negative consequences for the health of vulnerable groups such as children, women, workers in hazardous occupations, and elderly people. ${ }^{4}$ At the same time, the increase in cost sharing, reduction in the list of prescription drugs, the rise of the private medical sector, and other forms of personal costs for health care have shifted a proportion of health costs on to users. Out of pocket payments for health care have increased to such an extent that they are a substantial burden to many people, particularly those in lower socioeconomic groups. ${ }^{56}$

Privatisation of health services has created a two tiered system. In the growing private sector wealthy people can buy easy access to high quality services, whereas in the public healthcare system patients have to wait even for the basic services and have difficulties in obtaining the necessary drugs. With the restricted services covered by compulsory insurance and increased cost sharing, low income groups are at particular disadvantage in terms of access to health care. ${ }^{78}$

Thus, although the objectives of the health service reforms had been clearly set, no account was taken of users' needs, attitudes, and expectations. In pursuing the macroeconomic goals of the reforms, the government often neglected the interests and needs of those for whom the health service is created-the people themselves.

\section{Impact of the reforms from the perspective of users}

In central and eastern European countries, as in more developed countries, healthcare systems are rarely evaluated from users' perspectives. This might be because governments' objectives in reforming health policy are primarily to reorganise financing and to contain costs, which is often reduced simply to cutting spending, ${ }^{9}$ whereas users' interests are often not high on the political agenda. However, the World Health Organization European Regional Office has drawn up principles for healthcare reform that emphasise consumer rights and people's views. ${ }^{10} 11$ Thus, the
Ljubljana Charter on Reforming Health Care stresses that the fundamental principle of healthcare reforms should be to address people's needs, taking into account their expectations about health and health care. The public's views should be as important in shaping health services as those of decision makers. ${ }^{12}$

In Croatia several studies in the past 10 years have surveyed users' satisfaction with the health services and their views of out of pocket expenses, access to services and drugs, and healthcare reforms.

\section{Users' satisfaction}

In 1994, soon after the start of the healthcare reforms, a large proportion of Croatian citizens were dissatisfied with health services in general (44\%) and with the quality of health facilities and equipment in particular $(48 \%))^{5}$ The commonest reported reasons for dissatisfaction were the behaviour of healthcare staff (20\%) and long waiting times (19\%). More than a half of the respondents $(56 \%)$ did not understand the objectives of healthcare reform, and a large proportion (40\%) believed that reform had worsened their position as patients. ${ }^{57}$

The study revealed substantial social inequalities in access as reported by citizens. Those with lower education (up to primary school level) were more likely to report dissatisfaction with health services, difficulties in obtaining drugs, and social inequalities in access to services. On the other hand, those with university level education were more dissatisfied with the quality of facilities and equipment. Lower income groups were more dissatisfied with health services and reported more difficulties in access. Also, a high proportion $(31 \%)$ of respondents-particularly older people, women, and those with lower education or lower income-considered patients' copayments for various health services to be high or very high. Overall, $50 \%$ of respondents-particularly women and those with lower education-thought that copayments for health services and drugs were a major problem.

\section{Healthcare costs}

To describe the burden of out of pocket healthcare costs on individuals in different income groups, we used data from the 1994 study. ${ }^{6}$ Most respondents $(66 \%)$ reported having considerable costs, but people with low incomes were significantly more likely to do so. Analysis of different forms of direct payments revealed that $52 \%$ of respondents reported copayments for any kind of public health service, 49\% reported payments for visiting a general practitioner. and 43\% reported payments for prescribed drugs, whereas only $9 \%$ reported having copayments for hospital care. Analysis by income showed that low income groups reported more copayments than did high income groups (for example, $37 \%$ v $30 \%$ for visits to specialists, and $64 \%$ v $55 \%$ for prescribed drugs).

Other expenses included various forms of private payments for discretionary and elective health care, such as paying for private medical care and over the counter drugs or traditional medicine. Respondents also reported informal payments to healthcare providers such as gifts (14\%) and "gratitude money" $(8 \%)$. Low income groups reported significantly more expenses for drugs, private medical practice, private dental care, traditional drugs, and gifts and gratuities to healthcare providers. 
Table 1 Users' perceived impact of healthcare reform on provision and quality of care in Croatia in 2000

\begin{tabular}{lc} 
Statement & $\begin{array}{c}\text { Agreement with } \\
\text { statement (\%) }\end{array}$ \\
\hline Health care is better now than before changes & 13.7 \\
\hline Health care is the same now as before changes & 29.6 \\
\hline Health care is worse now than before changes & 40.8 \\
\hline Don't know & 15.8 \\
\hline
\end{tabular}

Table 2 Users' dissatisfaction with health services in Croatia in 2000

\begin{tabular}{lc} 
Aspect of health service & Dissatisfied (\%) \\
\hline Health services in general & 34 \\
\hline Family medicine & 19 \\
\hline Specialist care & 39 \\
\hline Dental care & 30 \\
\hline Hospital care & 47 \\
\hline Pharmacy & 16 \\
\hline
\end{tabular}

The results showed that the burden of out of pocket costs were not equally distributed among different socioeconomic groups, with lower income groups bearing a heavier burden than higher income groups.

\section{Perceived quality of health care}

A study from 1999-2000 collected data through face to face interviews with 500 randomly selected adults aged 40 years or more from all regions of Croatia (unpublished data). The questionnaire, based on the MOS-20 and QUOTE (version for the elderly) questionnaires, ${ }^{13}{ }^{14}$ asked interviewees about their satisfaction with health services, health insurance, private payments for health care, and background information. The net response was $393(79 \%)$.

The QUOTE analysis revealed what respondents considered to be the most important aspects of health services: healthcare providers should work efficiently; their waiting and consultation rooms should be easily accessible for disabled people; they should always respect patients' privacy; they should always inform patients, in understandable language, about drugs prescribed; and they should always explain the risks involved in any treatment. Those aspects each scored 8.1 or higher on a 10 point scale.

The aspects of health care that scored lowest $(<3.7)$ in importance for respondents were communication between healthcare providers, assessment of the costs and benefits of treatment, and arrangements about what to do in emergencies. Almost half of the respondents believed that healthcare reform had had a negative impact on the quality of health services (table 1 ), and the greatest dissatisfaction was reported with hospital care (table 2).

\section{Health inequalities}

Inequalities existed even in the ideologically egalitarian socialist healthcare system of the former Yugosla-

Table 3 Distribution of income level among 11250 Croatian people in 2003 by self reported health status. Values are percentages of respondents in each health group

\begin{tabular}{lccccc} 
& \multicolumn{5}{c}{ Health status } \\
\cline { 2 - 6 } Income group & Excellent & Very good & Good & Fair & Poor \\
\hline High & 57.3 & 60.1 & 41.2 & 31.6 & 18.1 \\
\hline Middle & 29.0 & 28.0 & 33.8 & 35.7 & 30.8 \\
\hline Low & 13.8 & 11.9 & 25.0 & 32.7 & 51.1
\end{tabular}

Difference between groups: $\chi^{2}=866.618, P<0.001$.

\section{Summary points}

Healthcare reform in Croatia resulted in transformation of a system based on a national health insurance model (with a high degree of equity and a virtually "free" services but with insufficient financial resources) into a system in which health services are market goods that consumers buy

Measures aimed at cost containment included rationing of services, limiting the services provided, a limited list of approved drugs, reduced health budgets, and increased copayments by patients

Out of pocket payments for health care have increased so that they are now a substantial burden, particularly to people with low incomes

Privatisation of health services has created a two tiered system in which wealthy people can buy easy access to high quality services in the private sector, whereas in the public healthcare system patients have to wait even for basic services and have difficulties in obtaining drugs

Surveys of users' views have revealed widespread dissatisfaction with the healthcare reforms and belief that the reforms have led to a worsening of the position of Croatian healthcare users

via. ${ }^{15}$ However, despite the new democratic Croatian government accepting the basic principles of a social state, the healthcare reforms oriented towards privatisation of the health services have increased social inequalities in health and use of health services.

In the recent adult health survey of a representative sample of the Croatian population in 2003, significant inequalities were found between different social groups in self reported health status (table 3). ${ }^{17}$ Because of the policy measures aimed to protect the most vulnerable groups, there were no significant inequalities in the use of health services. However, when the use of health services was controlled for by health status, significant inequalities between low and high income groups were observed. People reporting poor health and low incomes used significantly less specialist services than those reporting poor health but higher incomes (table 4).

\section{Conclusion}

Healthcare reform in Croatia might be seen as a transformation of a system based on a national health insurance model (with a high degree of equity and a virtually "free" services but with insufficient financial resources) into a system in which health services are considered market goods for which consumers have to know and pay the price. The Croatian government

Table 4 Distribution of use of specialist care among 11250 Croatian people with self reported poor health in 2003 by income level. Values are percentages of respondents in each income group

\begin{tabular}{lccc}
\multirow{2}{*}{$\begin{array}{l}\text { No of visits to specialist } \\
\text { in past year }\end{array}$} & \multicolumn{3}{c}{ Income group } \\
\cline { 2 - 4 } & Low & Middle & High \\
\hline None & 36.5 & 29.5 & 26.1 \\
\hline $1-2$ & 26.3 & 22.9 & 26.1 \\
\hline $3-4$ & 17.1 & 17.7 & 20.7 \\
\hline $5-10$ & 12.7 & 16.3 & 13.0 \\
\hline$>10$ & 7.4 & 13.5 & 14.1 \\
\hline
\end{tabular}

Difference between groups: $\chi 2=27.692, \mathrm{P}<0.001$. 
decided to rationalise the healthcare system without taking much account of the impact of the reforms on its citizens. The dissatisfaction among Croatian citizens with these reforms indicates that decision makers should consider users' opinions during health service reform if they wish to build a system that is not only cost efficient but is also responsive to citizens' needs, expectations, and health status.

Contributors and sources: MM is a medical sociologist who has been analysing health systems reforms over the past 20 years. His primary interest is in health inequalities. SK has been researching patient perspectives and health communication in general. The arguments found in this article are mainly based on published papers on health reform in Croatia and government documents.

Competing interests: None declared.

1 Orešković $\mathrm{S}$. Health system reorganization in Croatia in the light of major reform tendencies in OECD countries. Croatian Med J 1995;36:47-54.

2 Sarić M, Rodwin VG. The once and future health system in the forme Yugoslavia: myths and realities. J Public Health Policy 1993;14:220-37.

Hebrang A. Reorganization of the Croatian health care system. Croatian Med J 1994;35:130-6.

Orešković S, Kuzman M, Budak A, Vrcić-Keglević M, Ivanković D. Doctor in the house: trends in GPs home visiting in Croatia 1990-1995 compared to current trends in USA and UK. Coll Antropol 1997;21:595-608.
5 Mastilica M, Chen M-S. Health care reform in Croatia: the consumers' perspective. Croatian Med J 1998;39:256-66.

6 Mastilica M, Bozikov J. Out-of-pocket payments for health care in Croatia: implications for equity. Croatian Med J 1999;40:152-9.

7 Chen M-S, Mastilica M. Health care reform in Croatia: for better or for worse? Am J Public Health 1998;88:1156-60.

8 Mastilica M, Babić-Bosanac S. Citizens' views on health insurance in Croatia. Croatian Med J 2002;43:417-24.

9 Maarse H. Cost containment in health care: a brief overview. Antidotum Supplement 1995;1:56-65.

10 Vienonen M. Overview of the principles in health care reforms on the European scene. Antidotum Supplement 1995;1:107-10.

11 World Health Organization. European health care reforms: analysis of current strategies. Copenhagen: WHO Regional Office for Europe, 1996.

12 World Health Organization. European health care reforms: The Ljubljana charter on reforming health care. Copenhagen: WHO Regional Office for Europe, 1996.

13 Stewart AL, Hays RD, Ware JE. The MOS short-form general health survey: reliability and validity in a patient population. Med Care 1988;26:724-35.

14 Sixma HJ, van Campen C, Kerssens II, Peters L. OUOTE-health care services: quality of health care services from the user's perspective. Utrecht: Netherlands Institute of Primary Health Care, 1996.

15 Mastilica M. Health inequalities and health system change in former Yugoslavia. Int J Health Sci 1992;3(3-4):195-203.

16 Mastilica M. Health and social inequities in Yugoslavia. Soc Sci Med 1990;31:405-12

17 Béland Y, Bailie L, Page J. Statistics Canada, Croatian Ministry of Health, and Central Bureau of Statistics: a joint effort implementing the 2003 Croatinn aduthealth survey. Procedings of the American Sintistical Ass Croatian adult health survey. Proceedings of the American Statistical Associction meeting, survey research methods. Toronto: American Statistical Associa-
tion, 2004 .

\section{Commentary: Patients' empowerment: the East side story}

\section{Piotr Mierzewski}

Department of

Health and of the

Partial Agreement

in Social and Public

Health Field,

Directorate General

III-Social

Cohesion, Council

of Europe, 67075

Strasbourg-Cedex,

France

Piotr Mierzewski

administrator

piotr.mierzewski@ coe.int
The report by Mastilica and Kušec on citizens' dissatisfaction with the Croatian healthcare system ${ }^{1}$ could have also been set in almost any other country in transition. The transition from "real socialism" to "real prices" has been more difficult and painful than expected. Socialism has become a bad concept-and so have social concerns. In reaction to the previous totalitarian regime, commanding and controlling all social systems, the state has withdrawn from many social responsibilities. This has enabled various interest groups-doctors among them-to shape public opinion.

The public was also largely shaped by the legacy of "Homo sovieticus"-a passive, obedient citizen who trades freedom for safety and who is void of personal initiative and self determination, a citizen who expects, even demands, everything from the state. The forced transition to "Homo economicus" found many citizens who did not fully understand the rules of the new competitive environment feeling helpless. Ironically, "soviet" translates into "the people's council"-a body of direct democracy.

It is a symbolic paradox that social solidarity was among the first victims of the victory of the "Solidarity" (Solidarnosc) movement in Poland, as it was in many other states. Populations expected that universal access to free health services would remain after the transition, and felt betrayed when the market oriented reforms could no longer guarantee it. The social environment for citizens' empowerment was difficult in these new states for several reasons-lack of support from non-existing consumer movements, no tradition of organised lobbying, risk of reliance on funding from the pharmaceutical industry; failure to recognise conflict of interest as a serious issue, and, here and there, corruption. For many politicians, patients' empowerment and citizens' participation were seen as a luxury of wealthy nations-another "imported issue," like feminism or gay marriages.

Despite the rhetoric, there is still not enough noise about "choice and voice."' These issues are not reflected in the extremely useful World Health Organization's "health in transition" reports. In the reports on nine new "post-Soviet" members of the European Union the word empowerment doesn't appear at all; patients' rights are absent from three reports and mentioned only as short references to existing laws in five; and citizens' participation appears only in the report on Slovenia.

How do we get from the diagnosis to deeds? Empowerment means restoring a fair balance of power-but power is never given, only taken (Oreskovic. "The patient in the information age," presented at the fourth European Forum Gastein, 2001). An awakening of the silent majority might be stimulated by the three I's-information, involvement, and instruments. Governments may wish to adopt the comprehensive policy framework for "health democracy" elaborated in the Council of Europe recommendation on the development of structures for citizen participation in decision making processes affecting health care. ${ }^{3}$ A good first step for governments might be to stimulate public debates by commissioning inquiries and publishing reports on citizens' involvement in health care.

There is also much to do at the European level: reactivating WHO's "European partnership for patients' rights and citizens' empowerment"; promoting twinning of non-governmental organisations between the new and the old EU member states; establishing professional lobbying structures in Brussels; supplementing the existing "impact assessments" approach by measuring the impact on patients' and citizens' roles; and adding a patients' rights and 